UCRL-53204

Distribution Category UC-11, 66

\title{
Hot-Dry-Rock Energy: Review of Environmental Aspects
}

\author{
Kerry O'Banion
}

Manuscript date: October 13, 1981

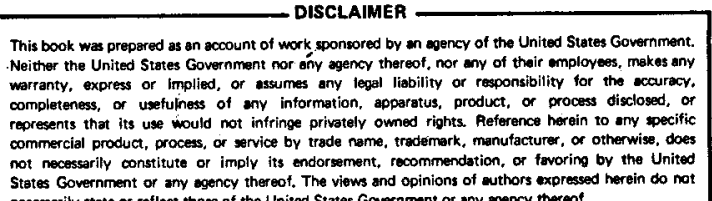

necessarily state or reflect those of the United States Government or any spency thereaf.

\section{LAWRENCE LIVERMORE LABORATORY University of California $\bullet$ Livermore, California $\bullet 94550$}




\section{DISCLAIMER}

This report was prepared as an account of work sponsored by an agency of the United States Government. Neither the United States Government nor any agency Thereof, nor any of their employees, makes any warranty, express or implied, or assumes any legal liability or responsibility for the accuracy, completeness, or usefulness of any information, apparatus, product, or process disclosed, or represents that its use would not infringe privately owned rights. Reference herein to any specific commercial product, process, or service by trade name, trademark, manufacturer, or otherwise does not necessarily constitute or imply its endorsement, recommendation, or favoring by the United States Government or any agency thereof. The views and opinions of authors expressed herein do not necessarily state or reflect those of the United States Government or any agency thereof. 


\section{DISCLAIMER}

Portions of this document may be illegible in electronic image products. Images are produced from the best available original document. 
Abstract . . . . . . . . . . . . . . . . . . . . 1

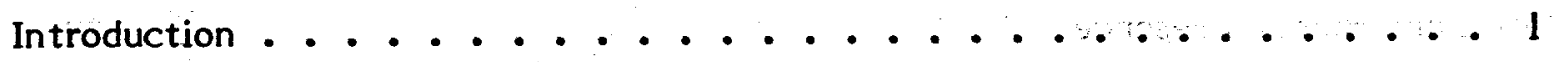

The HDR Energy Technology . . . . . . . . . . . . . . . 5

General Construction :. . . . . . . . . . . . . . . 5

Employment . . . . . . . . . . . . . . . . . 5

Landscape Disturbance . . . . . . . . . . . . . 6

Air Emissions . . . . . . . . . . . . . . . . 7

Noise .. . . . . . . . . . . . . . . . . . 8

Exploration ......................... 8

Resource Confirmation .................. . . 9

Site Preparation . . . . . . . . . . . . . . . . 9

Well Drilling . . . . . . . . . . . . . . . . . 10

Employment ....................... 10

Solid and Liquid Waste . . . . . . . . . . . . 12

Noise . • . . . . . . . . . . . . . . . . 12

Air Emissions . . . . . . . . . . . . . . . 13

Hydrofracturing . . . . . . . . . . . . . . 13

Water Use . . . . . . . . . . . . . . 14

Induced Earthquakes . . . . . . . . . . . . . . 14

Well Abandonment . . . . . . . . . . . . . . . 14

Field Development . . . . . . . . . . . . . . . . 14

Landscape Disturbance . . . . . . . . . . . . . 15

Energy Conversion . . . . . . . . . . . . . . . . . 16

Landscape Disturbance . . . . . . . . . . . . . 18

Water Use . . . . . . . . . . . . . . . . . 20

Solid and Liquid Waste . . . . . . . . . . . . . . 21

Air Emissions . . . . . . . . . . . . . . . . . . 22

Noise . . . . . . . . . . . . . . . . . 23

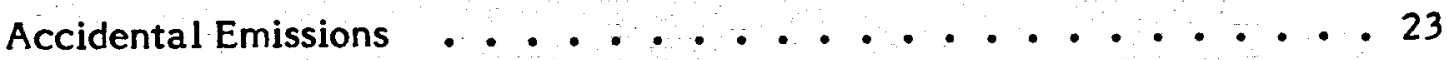

Employment ......................... 24

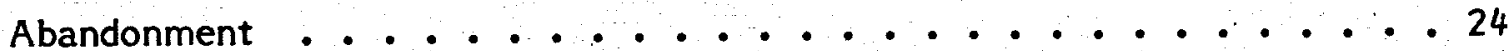


Potential Environmental Impacts . . . . . . . . . . . . . . 25

Landscape Disturbance ... . . . . . . . . . . 25

Water Use . . . . . . . . . . . . . . . . . 28

Noise and Human Presence . . . . . . . . . . . . 29

Air Emissions . . . . . . . . . . . . . . . . 29

Liquid and Solid Waste . . . . . . . . . . . . . . 29

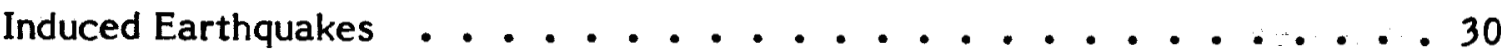

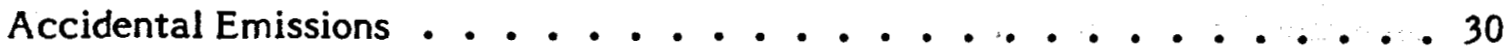

Potential Socioeconomic Impacts . . . . . . . . . . . . 31

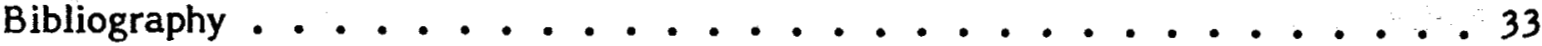




\section{ABSTRACT}

The potential environmental and socioeconomic impacts of the production of energy contained in hot dry rock (HDR) is surveyed here. In general, careful siting and timing and routine control measures should be adequate to prevent significant environmental harm; sites of particular ecological or visual and recreational value, however, may require more extensive (and more expensive) precautions such as using multiwell pads to reduce land disturbance and dry or wet and dry cooling towers to reduce or eliminate the consumptive use of water. The most important uncertainty among the environmental concerns is the seismic response of HDR formations to short-duration fluid injections at pressures above fracture thresholds; continued monitoring at HDR development sites is necessary. The direct socioeconomic impacts of HDR development should be relatively minor, owing to its capital-intensive nature. Of greater potential importance are the indirect jobs resulting from such development, which could cause significant demographic (and thus fiscal and social) impacts in sparsely populated regions. However, such indirect growth is not expected to begin until a large, stable HDR industry is established in a region, and thus its impacts are expected to be permanent rather than transient.

\section{INTRODUCTION}

The heat contained in rock within the earth's crust is a huge potential source of energy; given a conservative average temperature gradient of $22^{\circ} \mathrm{C} / \mathrm{km}, 13 \times 10^{21}$ Btus are estimated to be contained in the top $10 \mathrm{~km}$ of crustal rock within the U.S. alone. Recovery of only $0.2 \%$ of this amount would yield as much energy as is contained in the U.S. coal resource base. To date, utilization of geothermal energy has been limited to those few, unique sites where hot rock encounters natural groundwater. At those sites, wells are drilled to bring the steam and/or hot water to the surface, where it is used for process or space heat, to drive turbines to generate power, or both.

However, such natural hydrothermal reservoirs comprise only a minute fraction of the geothermal resource base. To exploit much larger hot dry rock resource requires (1) the creation of a large heat-transfer surface within the rock and (2) circulation of a fluid over the rock surface to extract its heat. While, at least conceivably, formations of permeable material could be exploited in this way, possibly through the use of water- 
drive methods long used in oil and gas recovery, research to date has been confined to low-permeability formations. This is because of the anticipated problems of fluid recovery in permeable formations and the fact that most sedimentary rock deep enough to be hot has been compacted by its overburden to a point of relative impermeability. Granites, which tend to be hotter than other rocks at the same depth because of their greater radionuclide content, are as a rule very impermeable, with natural water circulation limited to a few randomly oriented cracks (Garnish, 1978).

The HDR Geothermal Energy Project at Fenton Hill, New Mexico, funded by the Department of Energy (DOE) and conducted by the Los Alamos National Laboratory (LANL), is the first and, to date, the only field demonstration of hot dry rock (HDR) energy recovery. As shown in Fig. 1, an artificial geothermal reservoir was formed by drilling to suitably hot granite; creating a large, disk-shaped vertical fracture in the rock, using hydraulic fracturing methods routinely used to improve recovery from gas and oil reservoirs; drilling a second hole into the top of the fracture; and then closing the loop with heat exchangers at the surface. Cool water is injected through the first well, heated as it flows through the fracture, drawn up the second well and through the exchangers, and then reinjected. The water is kept as a liquid by pressurization at the surface; prevention of vaporization improves both the rate of heat removal from the rock and heat transport up the withdrawal hole (Pettitt, 1978; Nunz, 1980). The LANL is now at work on a larger phase 2 system at Fenton Hill capable of producing up to $50 \mathrm{MW}$, and is evaluating sites other than Fenton Hill for a third project.

The technology employed in the Fenton Hill project, that is, hydrofractured reservoirs in impermeable rock formations, is described in detail in the next section along with the equipment required to convert the heat extracted to a usable form. While other recovery methods for other rock media have been hypothesized, this report is confined to the former since it is so far the only technology demonstrated to be feasible.

While the quality of an HDR resource is a function of a number of factors including the permeability and porosity of formation rocks and their reactivity with water, the key factor is the geothermal gradient, or the increase in temperature per kilometer of depth. Gradients for the conterminous U.S. extrapolated by Kron and Heiken (1980) from well log data are shown in Fig. 2. To the extent gradients shown in Fig. 2 reflect actual conditions, HDR resources suitable for power generation would seem to be quite widespread in the U.S., located primarily but not exclusively in the western third of the country. Equipment and methods available today are routinely used to drill oil and gas wells to about $6 \mathrm{~km}$ in hard, hot rock at hole diameters large enough to accommodate the flow of a heat transfer fluid (Pettitt, 1978). If one takes $200^{\circ} \mathrm{C}$ as the lowest feasible rock temperature for power generation (Cummings et al., 1979), then an average gradient of only $33^{\circ} \mathrm{C} / \mathrm{km}$ would place such rock temperatures within reach of a $6-\mathrm{km}$ well. 


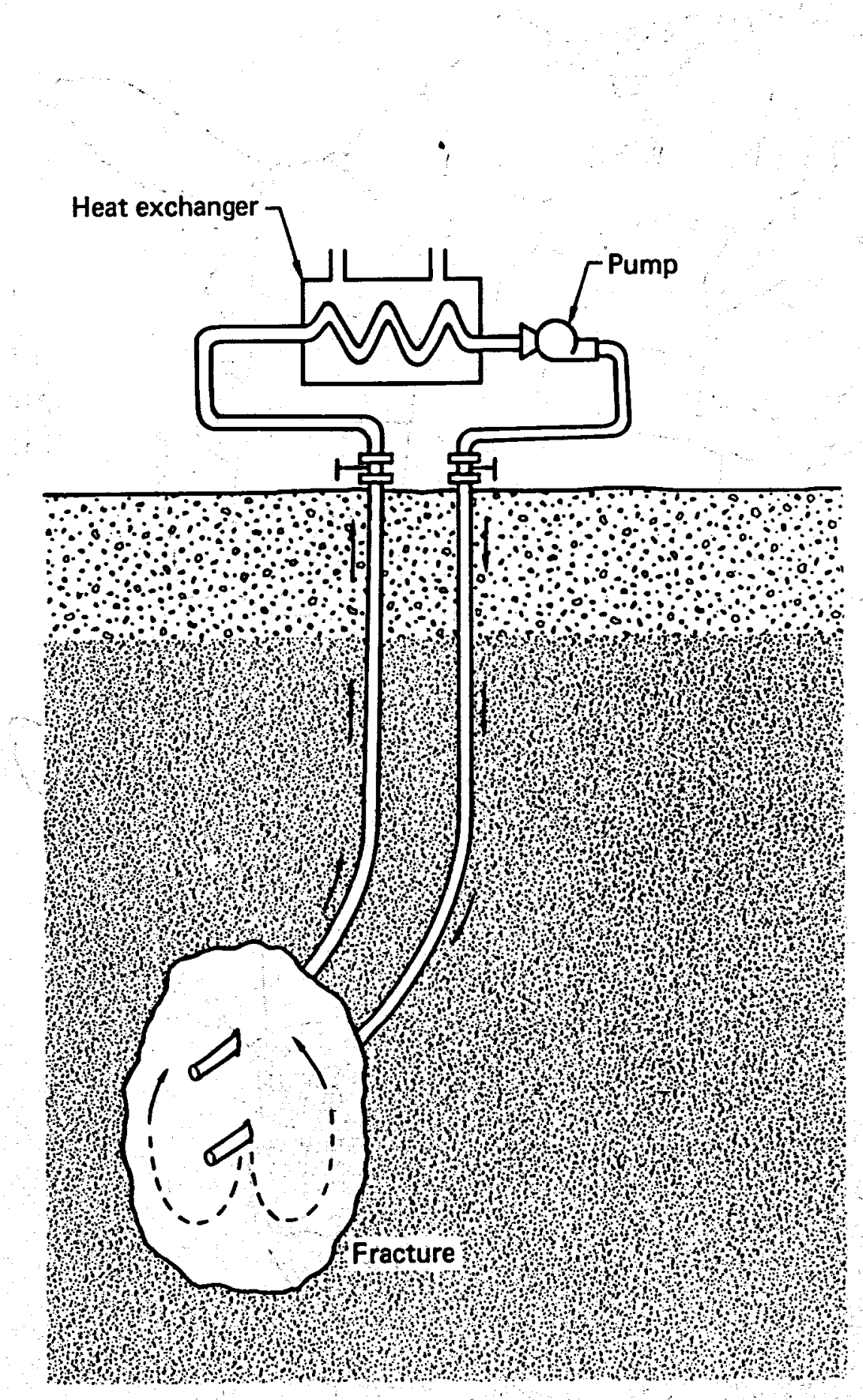

FIG. 1. Schematic of an HDR reservoir and circulation loop. 


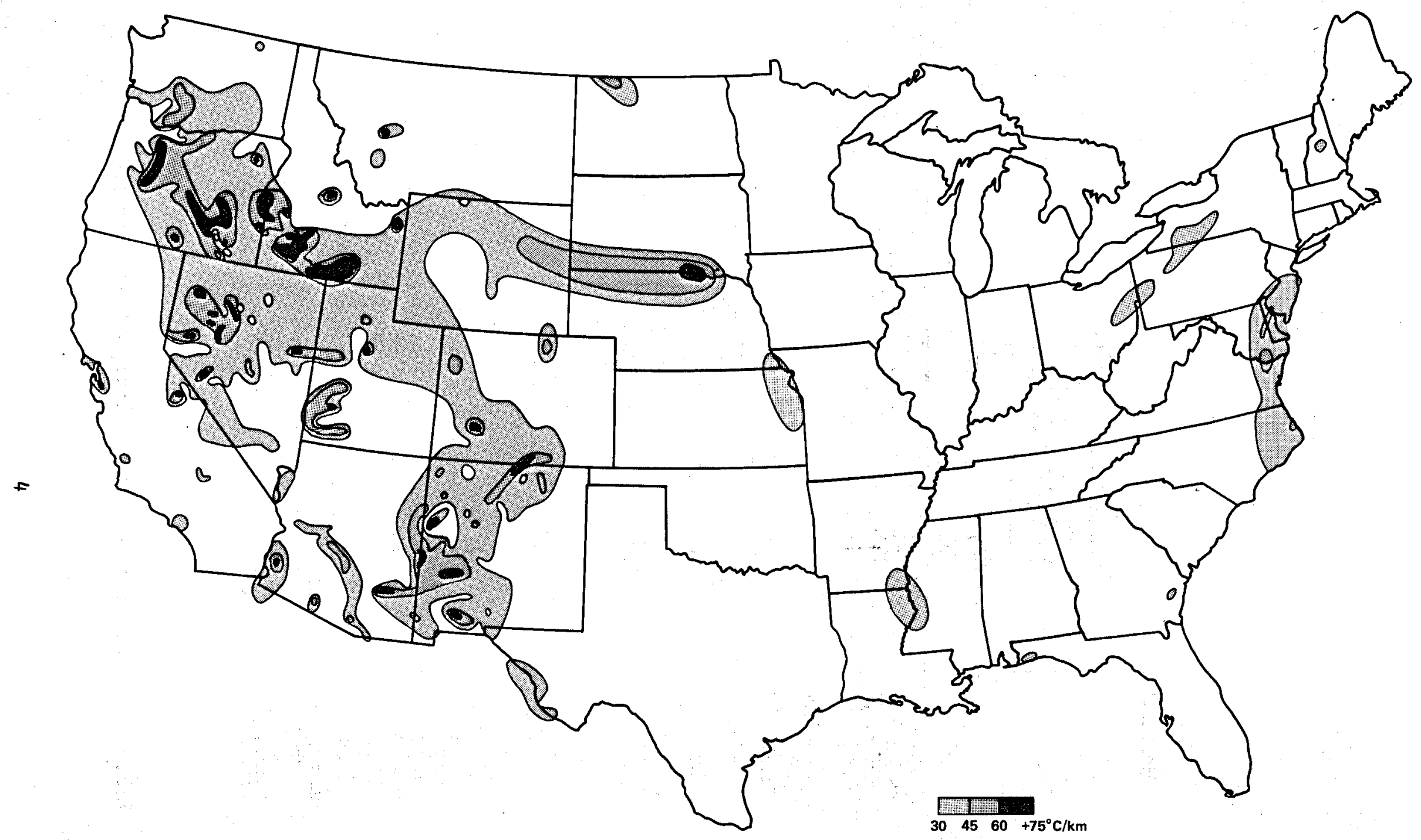

FIG. 2. Geothermal gradients of the conterminous U.S. (from Kron and Heiken, 1980). 
However, for HDR energy systems there are powerful incentives to minimize well depth: (1) the cost of a given well increases with depth at an exponential rate and (2) well drilling is expected to be by far the largest contributor to the total HDR system cost. In their HDR feasibility study Cummings and Morris (1979) found well drilling accounted for $49 \%$ of the total present-value cost of their $50-\mathrm{MW}$ e reference-case system. Thus while various factors exogenous to resource quality will unquestionably have some influence on the locational pattern of HDR development (the condition of the local utility's capital plant, its forecast energy demand, etc.), on the whole we expect development to be concentrated, at least at first, in the highest gradient areas.

\section{THE HDR ENERGY TECHNOLOGY}

Since HDR development is in fact a sequence of stages, we first describe its potential environmental impacts in the context of the sequence, that is:

- Exploration

- Resource confirmation

- Field development

- Energy conversion

- Abandonment

We also include one activity, general construction, that occurs in every stage. Following the stage-by-stage identification of environmental concerns, the concerns are grouped by types and analyzed with respect to:

- Major uncertainties

- Available control technologies

- Potential to impede HDR development

\section{GENERAL CONSTRUCTION}

General construction includes roads, pads, and mud sumps; structures and pipelines; and parking lots and storage areas. The tasks involved are site preparation (clearing, grading, soil compaction, etc.); building erection and demolition; and site maintenance.

\section{Employment}

The employment impacts of HDR systems are expected to be similar to those of hydrothermal systems described by Haven et al. (1980). Site preparation requiring a crew of up to 10 equipment operators and laborers per field is contracted out to a local firm; 
other local contractors may be hired to repair equipment, landscape the site, etc. Power plant construction extends over a period of about 2 y and employs a peak of about 80 workers for a 100-MW plant. Whether or not the demand for construction labor can be met within a given regional market depends on the pace of HDR development as well as the size of the market; but unlike well drilling (see Resource Confirmation, below), the skills required in general construction are common ones available in almost any locality. While all but the most sparsely populated markets should be able to provide the labor required for a single field and plant, the scheduling of a number of plants within a region could lead to some in-migration if construction time frames overlap or if the pace of HDR development is expected to continue to increase.

\section{Landscape Disturbance}

The HDR energy systems are expected to be similar to hydrothermal systems in the amount of landscape disturbed: namely, 10 to $20 \%$ of the entire site.

Alteration of natural contours and removal of vegetation combine to increase the susceptibility of soil to erosion; this is particularly serious in mountainous areas not only because runoff velocity is greater, but also because such areas require much more cutting and filling to provide level roads and pads. Erosion impacts both land ecosystems by removing topsoil and aquatic ecosystems by increasing sediment and nutrient loads. The sediment interferes with fish respiration and obstructs penetration of light into water, hindering the ability of fish to locate prey and reducing photosynthesis in aquatic vegetation. Sediment may also invade spawning areas, discouraging reproduction, and may be deposited at the mouths of streams and rivers, altering flow. An increase in soil nutrients to the water body can lead to eutrophication and subsequent oxygen depletion. Alteration of natural contours can also induce landslides in areas of steep terrain and unstable bedrock. As well as the damage they cause directly, landslides also increase soil erosion and change surface and subsurface drainage, particularly if slide material dams up watercourses.

On land, changes in nutrient cycles may result from increased aeration, exposure of subsurface soils to evaporation, and temperature changes having adverse impacts on microflora and microfauna. Some reptiles and burrowing mammals are lost as a direct result of construction activity; others disperse into the surrounding habitat where they are subject to predation or to starvation because of overpopulation. In general, carnivores and raptors are less vulnerable to localized disturbance because they range over wider areas, but they may lose their young if the disturbance occurs close to nesting loci 
(Woodward-Clyde, 1978). Linear features such as roads can fragment the habitats onsite into isolated segments that may not be viable, and resident small animals may be reluctant to cross the roads and thus expose themselves to predators.

Because the subsurface soils exposed by clearing and grading, erosion, and landslides a re in general coarsely textured and low in nutritive value, construction can permanently impair the ability of the land to sustain the vegetation mix that previously existed. Moreover, even if vegetation can restore itself over the long term, in most instances it must go through successional stages, each with its own unique mix of plant abundance and diversity. In ecosystems such as the desert where recoverability is low it can take decades for predevelopment conditions to return. Alterations of the physical structure and nutrient cycles of the habitat can in turn lead to shifts in faunal populations. Some species may benefit, for example, by the increase in ecotonal area from replanting devegetated land with grasses, while others may be lost because of the removal of cover.

Disturbance of the landscape can also damage its visual quality. In hilly terrain the scars created by cutting and filling for roads, pads, and sumps are visible for miles; so, on forested slopes, are the cleared firebreaks for surface fluid lines and the swaths beneath power lines where mature trees are cut back to expose the understory (see the discussion of fluid and power lines in Energy Conversion, below). This is an especial problem when the landscape has recreational value; not only do its users lose a source of pleasure, but if the local economy is tourism oriented, the income of residents can decline significantly. Because only a low percentage of land within an HDR wellfield must be disturbed, it is generally possible to avoid known historic or archaeologic resources even when they are located within the field. Grading and excavation may, however, disclose resources not previously known.

\section{Air Emissions}

The use of heavy equipment produces both exhaust fumes and dust. Dust is produced by movement of vehicles on unsurfaced roads and by wind on cleared land, as well as by earth movement itself. Dust can inhibit vegetation growth and, at sites very close to water, can increase its sediment load. However, except under abnormal conditions such as a drought, dust as a rule extends no more than 20 to $25 \mathrm{~m}$ from its source.

The diesel engines that run heavy equipment emit $\mathrm{SO}_{x}, \mathrm{NO}_{x}, \mathrm{CO}$, unburned hydrocarbons, and particulates; but the quantities are insignificant. For example, two pieces of equipment working for $5 \mathrm{~d}$ and using $500 \mathrm{gal}$ of fuel in building one pad would emit $13.5 \mathrm{lb} \mathrm{SO}_{x}, 185 \mathrm{lb} \mathrm{NO}, 112.5 \mathrm{lb} \mathrm{CO}, 18.5 \mathrm{lb}$ hydrocarbons, and $6.5 \mathrm{lb}$ particulates. 
Noise

Road building equipment emits noise in the range of 80 to $90 \mathrm{dBa}$ at $15 \mathrm{~m}$, which attenuates $6 \mathrm{dBa}$ with each doubling of distance from the source. The impact of noise on wildlife behavior is not well understood, but it is likely to be adverse for species that rely largely on sound for hunting, mating, or self-defense. Animals are also likely to be more sensitive to noise and human intrusion at certain points in their life cycles, such as during mating or nesting. On the other hand, there is ample evidence many species become conditioned to quite loud noises when they are repeated or sustained over a period of time (Goodwin, 1975). How objectionable the noise is to humans in the vicinity is a function of the background noise level and the type of activity they are engaged in. However, at least in recreational and quiet residential areas the noise produced by construction would significantly detract from their use. (See also the discussion of drilling noise under Resource Confirmation.)

\section{EXPLORATION}

As well as aerial surveys and reviews of existing data from maps, well logs, etc., exploration of a potential HDR resource involves a variety of onsite geochemical and geophysical studies, among them the drilling of 10 to 30 shallow $(<150 \mathrm{~m})$ holes to measure heat flow. A truck-mounted rotary drill is used to drill the shallow holes; water gel or a clay-based mud is used to cool the bit and bring cuttings to the surface and a sump or portable tank is used to contain the recirculating fluid. The drilling of each shallow hole will disturb a land area of about $90 \mathrm{~m}^{2}$. A temporary road to each site may also have to be cleared. Other potential impacts are noise from human and vehicular activity as well as the drill rig itself, soil erosion on the disturbed area, and possible spillage of fuel and lubricants.

The next step for the developer is to drill four to six slim holes $<0.1 \mathrm{~m}$ in diameter and up to $1.5 \mathrm{~km}$ deep. Cores taken from the slim holes provide data to estimate the temperature, porosity, conductivity, fracture response, and mineralogy of the HDR formation. A portable rig is used to drill the slim holes, with environmental impacts very similar to those of shallow holes.

Aside from the drilling operations, impacts in the exploration phase are confined to those caused by the transport of field crews (of up to 15) and their equipment in cars and trucks and by the crews' camps, if lodging is not available nearby. The impacts of both should be transitory and insignificant as long as vehicles are restricted to roads and trails 
and responsible camp practices are followed. Off-road use of vehicles, however, can result in localized damage: it disturbs topsoil and thus interferes with nutrient cycling, destroys vegetation, compacts the soil, creates ruts that accelerate runoff and thus soil erosion, causes sedimentation in crossing streams, and introduces noise to otherwise quiet environs:

\section{RESOURCE CONFIRMATION}

If near-surface conditions indicate a viable HDR resource exists at depth, the next step is to drill an exploratory hole to the target formation. Its temperature is recorded and various experiments are performed on the rock to determine its permeability and fracture response. If the formation is judged suitable for HDR energy recovery, the hole is extended to virgin rock and the fracture propagated. A second hole is then drilled to intersect the fracture, and circulation tests performed to determine the size, orientation, and other characteristics of the reservoir system (Pettitt and Tester, 1978). (In the field development phase, once the fracture response of the rock is known, both holes may be drilled before the fracture is propagated.)

\section{Site Preparation}

A cleared, leveled, compacted pad of about 0.8 ha is required for the rig and other equipment to be set up. (In the field development phase, however, several deviated well pairs can be drilled from a single, larger pad.) A sump must be dug next to each pad for the storage of waste cuttings, drilling fluid (mud or water gel), and water used to fracture the rock and test the performance of the reservoir. There is also a risk unanticipated hydrothermal fluid may be encountered in drilling that could, if under sufficient pressure, rise to the surface; it would also be deposited in the sump. Because drilling deep wells requires heavy equipment (rigs, generators, etc.), roads must be built both from the nearest existing road to the site and also between each well pad if there are more than one. (Impacts of road, pad, and sump construction are covered in General Construction, above.)

If a town with accommodations is nearby, the drilling crew is housed there, but in remote areas accommodations must be provided onsite in house trailers, campers, or tents. A site for the trailers and tents must be cleared and leveled, but because of the scale and limited duration of the camp, its potential impacts are generally minor as long as construction and sanitation are responsibly managed. 


\section{Well Drilling}

Heavy-duty oil rigs powered by diesel generators are run $24 \mathrm{~h} / \mathrm{d}$. Air, water, or any of various clay-based muds may be used to cool the bit and transport cuttings to the surface. The cuttings, along with waste drilling fluid and any natural fluids encountered in situ, are deposited into the sump (Fig. 3). Mud and water drilling have considerable advantages over air drilling: better lubrication and temperature control, longer bit life, and safer conditions for workers. However, muds begin to degrade at temperatures above $120^{\circ} \mathrm{C}$ (Prestwich, 1980) and breakdown is rapid at temperatures above $200^{\circ} \mathrm{C}$. Since the temperatures of most HDR reservoirs will exceed this limit, in those instances the driller would either have to use water or air throughout or switch to one or the other at some point in the job. At Fenton Hill, mud was used to drill through the volcanic and sedimentary rocks overlying the granite. Air was used at first to drill through the granite, but when the drillers found it difficult to keep the hole dry, water gel was substituted for air and was found to reduce bit wear and improve penetration rates (Mortensen, 1977). The water required may either be obtained from a nearby water body or aquifer or hauled to the site in tanks.

Employment. Drilling is generally contracted out by the developer to rig operators who employ a core of regular employees who travel with a rig wherever it goes. Each rig requires 21 to 25 workers divided into 4 crews of 5 to 6 people each plus a rig supervisor. In The Geysers region in California, where quite intensive hydrothermal development is expected to continue for many years, a skilled labor pool of some 250 to 300 drillers live in the region (although the individuals in the pool change constantly as some rigs are moved outside the region and others are moved in). Similar labor pools may eventually form in HDR resource areas, particularly high-gradient areas. At least for the first generation of demonstration plants, however, rigs and crews will be imported for the job and leave the area once it is complete. Since the deregulation of oil and gas prices, rigs are in great demand, and even if future jobs are anticipated in an area, the rig operator cannot afford any slack time. Given the size of the crews, the relatively short duration of their stay in the area, and the fact that very few crewmen have families traveling with them, their impact on the local economy, services, and cultural fabric should be insignificant (Haven et al., 1980).

Of greater significance than the direct employment from drilling and its related tasks is the indirect and induced employment it brings about. As defined in the study by Lofting and Hall (1981) of the economic impacts of hydrothermal development at The Geysers, indirect employment refers to jobs created in other sectors to supply the sector 


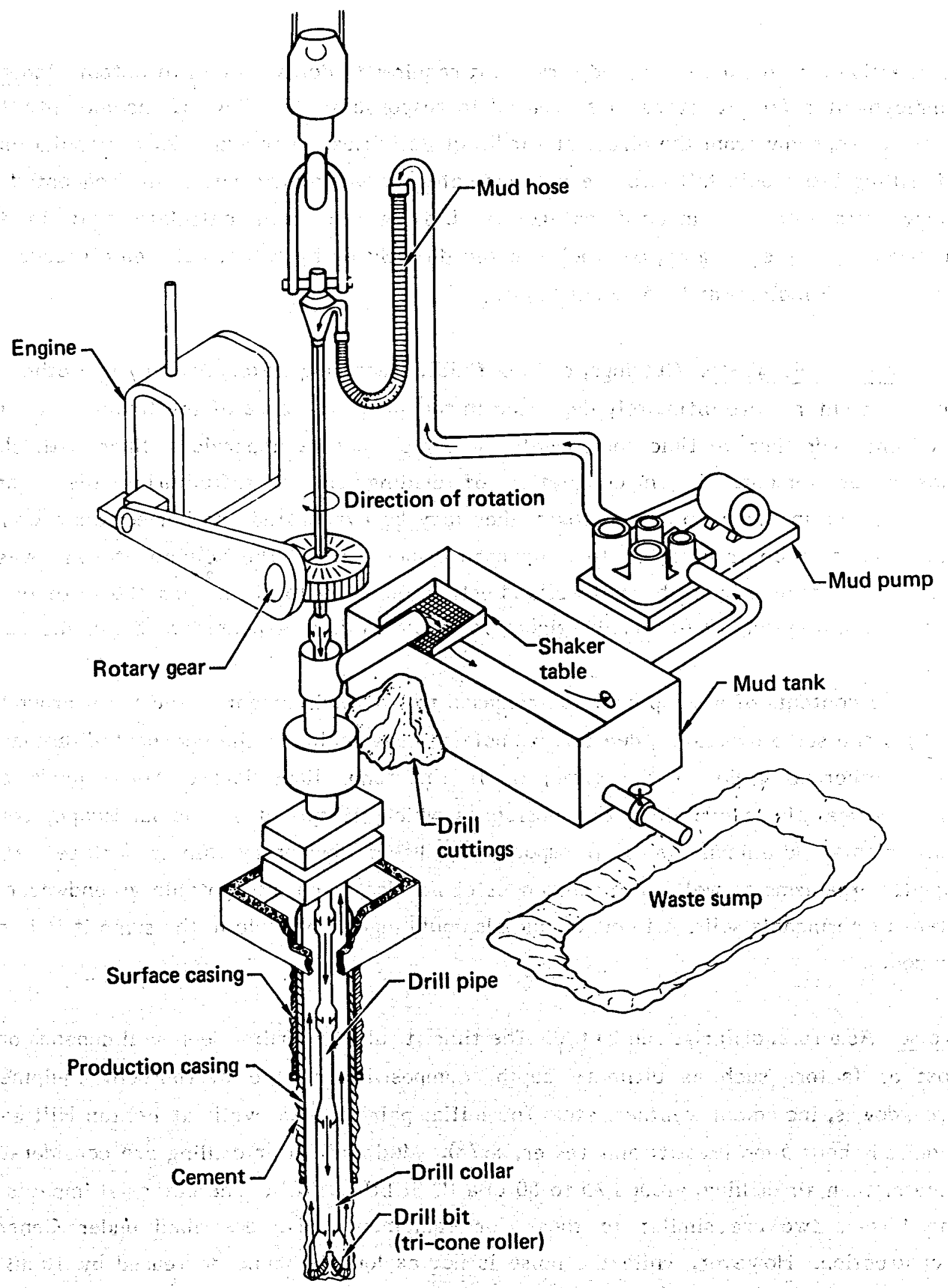

FIG. 3. Typical rotary drilling equipment. 
in question with the materials and services it requires to deliver a unit of output. Induced employment refers to other jobs created in response to the flow of income into the regional economy from the direct and indirect activities. (For example, a manufacturer of drilling bits would fall into the indirect category, a country-music bar frequented by rig workers into the induced category.) Lofting and Hall calculate that in the four-county Geysers region, each job created directly by hydrothermal steam production results in 4.3 indirect and 2.5 induced jobs.

Solid and Liquid Waste. Cuttings, drilling fluids, fracturing water, and any hydrothermal fluid encountered are ultimately deposited in the sump. Because of the toxicity of some mud and hydrothermal fluid components the sump must be impervious, lined with clay, plastic, or cement. If on completion of drilling and hydrofracturing the wastes accumulated in the sump are nontoxic, they may be evaporated and buried; toxic waste, however, must be transported to a licensed disposal site. The volume of solid waste produced in drilling hydrothermal wells is estimated as 20 to $40 \mathrm{~m}^{3}$ per $100 \mathrm{~m}$ of depth (Morris and Layton, 1980) and the figure for HDR wells is expected to be in the same range.

The contents of a sump could be released to the environment if the berm around it fails; if the sump overflows, due for example to heavy rains or the unexpected discharge of hydrothermal fluid to the sump; or if the sump liner leaks. Some muds and hydrothermal fluids contain toxic substances which, if spread on the landscape, could harm plants and animals and if transported by direct flow or by rain to surface water, aquatic organisms as well. The substances could also leach into potable groundwater in areas of permeable soils. Of course, animals could ingest the fluid in the sump if it is not fenced.

Noise. As a rule, drill rigs run $24 \mathrm{~h} / \mathrm{d}$. The time it takes to drill a deep well depends on a host of factors such as ultimate depth, composition of the overburden, equipment breakdowns, inclement weather, etc. The initial pair of $3-\mathrm{km}$ wells at Fenton Hill each required about 5 mo (Pettitt and Tester, 1978). Mud and water drilling are considerably quieter than air drilling, around 75 to $80 \mathrm{dBa}$ (U.S. EPA, 1977). The potential impacts of the former two are similar to those for equipment noise described under General Construction. However, while the noise is not as loud (a sound decreased by $10 \mathrm{~dB}$ is perceived as only half as loud), it may be more objectionable to humans in the vicinity because it is not limited to daytime. 
With no muffling the noise produced by air drilling can reach $120 \mathrm{dBa}$, the pain threshold for humans, at $8 \mathrm{~m}$. The noise can be reduced to 85 to $95 \mathrm{dBa}$ by directing the blooie line, the main source of noise, into the air chamber (U.S. EPA, 1977). At this level, the noise impacts are comparable to those described in General Construction.

Air Emissions. The air emissions from the diesel generators are the same as those described in General Construction and are similarly insignificant in quantity.

\section{Hydrofracturing}

Once the target formation is reached by the first hole, a series of experiments is performed on the rock to determine its permeability and fracture response. If the formation is judged suitable for an HDR reservoir, the hole is extended into a new region of the formation and cased to within a few meters of the bottom. Water is then pumped down the hole and held at a sufficient pressure for a sufficient time to fracture the rock. Once the fracture is completed, pressure is released and the water is discharged to the sump.

Water Use. The amount of water required for hydrofracturing depends on both the permeability of the formation and the desired fracture size. It is estimated 2000 to $4000 \mathrm{~m}^{3}$ will be required for each of the multiple $300-\mathrm{m}$-radius fractures in the phase 2 system at Fenton Hilf however, the same water can be reused again and again (Smith, 1981). Actual consumption is thus limited to the amount required for the initial fracture plus the makeup water required to replace permeation loss in subsequent fractures. Again, the water may either be obtained from a nearby water body or aquifer or trucked in.

Induced Earthquakes. There is some concern that hydraulic fracturing may enhance seismic activity. The concern originates from two incidents in Colorado at Rangely and near Denver, linking high-pressure injection of fluids with earthquakes. At Rangely, the existence of a threshold formation pressure was demonstrated. It was shown that by raising the injection pressure above the threshold, earthquakes could be induced, evidently caused by a decrease in the physical strength of the rock (Raleigh et al., 1975). The mechanisms for the decrease in rock strength include forcible lubrication of fracture planes and dilatation, or an increase in pore pressure to the point of rock fracture (Layton and Crow, 1980). 
Both Colorado incidents entailed prolonged, sustained injection. In hydraulic fracturing, on the other hand, above-threshold pressures are held for a few hours to, at most, a few days. This technique is used widely in the oil and gas industry to improve the productivity of low-permeability formations, and there is no documented evidence of perceptible earthquakes being induced. The Fenton Hill project is monitored by both a regional seismic net and onsite instruments. To date, no seismic events related to HDR activity have been detected by surface instruments sensitive to Richter magnitudes as low as -1 , which is too weak to be felt by humans by a factor of $10^{4}$ (Heiken et al., 1981). Microearthquakes of magnitudes -6 to -2 have been recorded by even more sensitive downhole instruments (Albright, 1979).

Since many HDR resource areas coincide with areas of moderate-to-high seismic risk, seismic monitoring at development sites will be necessary, at least until more evidence on the reponse of rock formations to short-duration fluid injection is compiled. The evidence to date, however, suggests the risk of induced earthquakes from hydrofracturing is very low (Layton and Crow, 1980; Crow, 1981).

\section{Well Abandonment}

If the well is successful it will be shut down temporarily, to be reopened later for production. If it is unsuccessful, a few more experiments may be performed, then it will be filled with cement and the site restored and abandoned.

\section{FIELD DEVELOPMENT}

The number of HDR reservoirs required for a production field depends on characteristics of both the HDR resource and the end use. The end use could be either heat or power generation or both. The following discussion (Cummings and Morris, 1979) is framed in the context of power generation because, as has been the case with hydrothermal energy, we expect it to dominate HDR development at least in the near future.

The number of reservoirs $N$ required by a plant of capacity $Q$ (in $M W_{e}$ ) is determined by the equation

$$
N=Q\left(M_{d} / m_{d}\right)
$$


where $M_{d}$ is the design flow rate of the plant and $m_{d}$ is the design well-flow rate. The plant design flow rate, in turn, is inversely related to its design temperature; the lower the fluid temperature, the greater the flow required.

A major problem of HDR energy is that because of the low thermal conductivity of the rock, natural heat flows toward the fracture at a much lower rate than it is withdrawn by the circulating water, and thus the temperature of the fracture surface will decline over time. The useful life of the reservoir thus depends on the well-flow rate relative to the fracture surface area. Since there is an obvious incentive to keep well-flow rates high, in order to minimize the plant design temperature (and thus the well depths required) there is also an incentive to maximize fracture surface area. This may be done by creating either a very large single fracture or a sequence of multiple fractures. Because of the low conductivity of the rock, fractures separated by more than $50 \mathrm{~m}$ show negligible thermal interference over 20 to 30 y (Cummings et al., 1979).

The life of an HDR system is not confined to the useful life of the initial fracture surfaces, however. One mechanism that may prolong system life is natural thermal contraction; as the fracture surfaces cool, the rock is likely to crack, expanding the total area of the reservoir. In the absence of thermal cracking, the existing wellbores could simply be extended or diverted to a new part of the formation and a new fracture or set of fractures created.

Therefore the number of reservoirs, and thus of well pairs, is only one variable in an optimization problem that also includes the temperature and surface area of the reservoirs and the operational features of the conversion plant as well as exogenous factors such as the prevailing discount rate. Cummings and Morris (1979), for example, present a reference case in which 11 well pairs are required to produce an output of $50 \mathrm{MW}$ under conditions felt to be representative of future development.

In field development the same general sequence of activities and thus of potential impacts described under Resource Confirmation and General Construction would be repeated for each well pair.

Landscape Disturbance. In the field development phase the use of multiwell pads can significantly reduce the amount of landscape disturbance per well. This practice has long been recommended as a way to reduce the impacts of hydrothermal development, but has not been adopted to date because of the greater cost of deviated wells. This is not expected to be as great an obstacle in the HDR case for two reasons. First, unlike hydrothermal wells, which as a rule are vertical, the HDR technology described herein 
requires wells to deviate from the vertical to intercept the vertical or near-vertical fractures. Second, also unlike hydrothermal wells, which must be comparatively widely spaced at depth, HDR reservoirs may be spaced as close as $50 \mathrm{~m}$ without thermal interference. Landscape disturbance caused by multiwell pads would be only a fraction of that caused by individual pads. For example, it is estimated that ten wells drilled from a single large pad would disturb only 20 to $30 \%$ as much land as would ten individual pads (Kercher and Layton, 1980), not counting the more extensive network of roads and fluid lines required to connect the latter.

\section{ENERGY CONVERSION}

The HDR energy systems will use conversion technology developed for hydrothermal systems, adjusted only to match the fluid temperature obtainable from the resource. If fluid temperature is above $150^{\circ} \mathrm{C}$, it may be used to generate electric power. Fluids below $150^{\circ} \mathrm{C}$ would, in general, be limited to direct thermal applications such as space or process heat. While we expect power generation to initially dominate HDR development as it has hydrothermal development, a huge market exists for direct heat as well; over a third of present U.S. energy consumption is in the form of heat, mostly at temperatures under $150^{\circ} \mathrm{C}$. Moreover with higher temperature fluids, enough residual heat may be left in the turbine discharge to provide some usable direct heat as well (Nunz, 1980).

The binary cycle is most suitable for converting HDR energy to electricity since it requires lower fluid temperatures than the alternative, flashed steam. In the binary cycle the fluid extracted from the HDR reservoir is drawn through a heat exchanger to vaporize a secondary working fluid; the vaporized working fluid is used to drive a turbine and then recondensed to a liquid (Fig. 4). Any of various organic fluids such as isobutane, isopentane, or the freons may be used as the working fluid. Each has a maximum efficiency at certain primary fluid and heat rejection temperatures, turbine sizes, etc. (Cummings et al., 1979).

Because of their inherently low conversion efficiency (10 to 15\%) and the large size of components such as heat exchangers, economies of scale for geothermal (hydrothermal and HDR) power plants are insignificant at capacities above $50 \mathrm{MW}$ (Cummings and Morris, 1979). As a consequence, unlike coal- or oil-fired plants, for which the optimal size is in the $1000-\mathrm{MW}$ e range, HDR plants are unlikely to be much larger than $100 \mathrm{MW}$, as is the case with the hydrothermal plants at The Geysers. Thus, while several such plants might be built at a large HDR resource, the impacts of power conversion would be relatively dispersed over the developed area. 


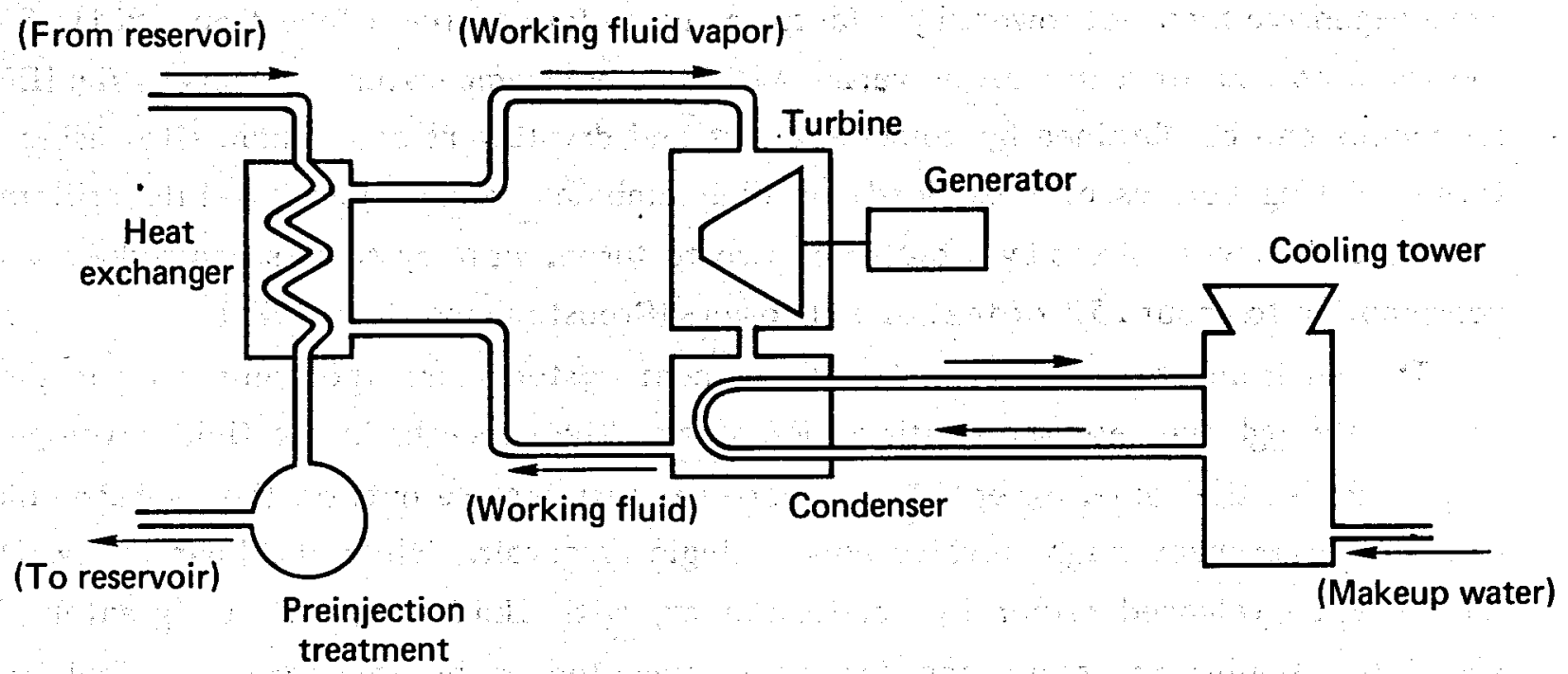

FIG. 4. Schematic of a binary HDR power plant.

The options available for heat rejection from HDR plants include once-through cooling from a natural water body, cooling ponds, cooling towers, and direct use of the waste heat. Few if any HDR plants are expected to use once-through cooling because of the large flow volumes required and environmental limits on thermal discharges to natural surface waters. The cooling pond, an artificial body of water built near the plant to function as a heat sink, avoids the thermal discharge problem but requires huge amounts of land. For conventional steam-driven plants, 0.6 to $0.8 \mathrm{ha} / \mathrm{MW}$ is a typical range (Probstein and Gold, 1978). However, geothermal plants discharge three to six times as much heat per $M W_{e}$ as do conventional plants and thus given the same site conditions would require on the order of 2 to $5 \mathrm{ha} / \mathrm{MW} \cdot \mathrm{e}$ Moreover, cooling ponds lose more water through evaporation than do wet cooling towers.

We expect cooling towers to be the rule for HDR plants, as has been the case for hydrothermal plants. The towers can be wet, dry, or some combination of the two. Wet towers transfer heat from condenser water to the air by evaporation. The hot water is sprayed down into the tower, and the heat lost in its evaporation is absorbed by air drawn up the tower by fans (mechanical draft) or by simple convection (natural draft). The water may pass through only once or it may be recirculated; with each pass a certain amount is lost through evaporation, drift, and blowdown (water removed to control the build up of solids) and must be replaced.

In dry towers, which may also be mechanical or natural draft, air is drawn over banks of finned tubes that contain the condenser water. No evaporation takes place; heat transfer is entirely by conduction. The amount of heat transfer per unit of air is lower 
and surface area requirements much greater than in wet towers, and thus dry towers are more expensive than wet towers by a factor of up to four to five (Robertson, 1981). Since the required size of a dry tower varies with ambient temperature, however, significant economies can be obtained by combining wet and dry towers at a single site, using the former during periods of peak loads or high ambient temperatures. While still more expensive than wet towers by a factor of two to three, wet/dry towers can reduce water consumption to about 25\% of that of wet towers (Probstein and Gold, 1978).

The environmental concerns for direct-heat systems are the same as for power systems through the resource confirmation stage. The concerns in the field development stage are also the same, except that direct-heat systems are not, on the average, likely to be as large; many might involve only a single reservoir. While the heat in the HDR fluid may be released either by conduction or, with fluid temperatures greater than $100^{\circ} \mathrm{C}$, by flashing to steam, the former is expected to be the norm, particularly in water-short regions. In conduction-type systems, the heat of the HDR fluid may or may not be transferred to a working fluid; in either case, however, the HDR fluid is contained in a closed loop as it is in power systems. As a means of heat rejection from power plants, direct-heat systems are similar to dry towers in that they consume no water and produce no effluents. Such systems could be used in combination with wet or dry towers provided, of course, some beneficial use for the heat exists within an economic distance.

\section{Landscape Disturbance}

A typical $100-M W_{e}$ geothermal plant requires a cleared flat site of about 4 ha; the amount of land disturbed, however, can range up to double this amount in hilly terrain. The surface fluid lines that connect the plant to the wellbores may be either above or below grade, although the former is expected to be the rule because of both its lower cost and the fact that leaks and breaks are more easily detected. If the fluid lines are in an area prone to wildfires, vegetation within about $3 \mathrm{~m}$ on both sides may be removed to create a firebreak. Low vegetation, primarily grasses, is maintained by cutting, use of herbicides, or both. Unless used with care, herbicides can cause death or reduced reproduction in nontarget organisms. Although fluid line right-of-ways are themselves too narrow to support a grassland vertebrate fauna, the increase in productivity they cause in the forest or brushland margin could partly compensate for the loss of vegetational structure in the right-of-way. On the other hand, if the fluid lines are laid out in a crisscross manner, they could disrupt the movement of both small and large animals. Small animals may be reluctant to cross the right-of-ways because of the lack of cover, while the migrations of large animals can be blocked by the lines themselves 
unless vertical expansion loops are built to allow their passage. The land area disrupted by the surface network of fluid lines for an HDR plant should be of about the same magnitude as for a hydrothermal plant: up to $5 \mathrm{~km}^{2}$ per $100-\mathrm{MW}$ e plant (U.S. DOE, 1977).

The plant is connected to the local electrical grid by 230-kV lines supported on steel lattice towers 15 to $30 \mathrm{~m}$ high with spans of about $360 \mathrm{~m}$. Access roads must be built to each tower base site and about $1000 \mathrm{~m}^{2}$ of land cleared to permit construction and servicing of the tower. Natural vegetation beneath the wires is left in place, but must be trimmed periodically to keep it at least $3 \mathrm{~m}$ from the wires. Since the minimum ground clearance for the wires is $10 \mathrm{~m}$, even at its lowest points in forested areas the understory vegetation and very young saplings should be undisturbed (SRI, 1977). Maintenance of low vegetation on power line right-of-ways that pass through forest land will affect the diversity and abundance of wildlife. Although the diversity of wildlife within the right-of-way itself may be higher or lower than within the forest, the diversity in the area containing the right-of-way will likely increase due to the migration of species that prefer low vegetation (e.g., larks, starlings, or microtine rodents). Such habitats have become abundant due to the changes man has induced in the natural landscape, and as a result species associated with right-of-ways tend to be common ones. Right-of-way construction can thus have the negative impact of displacing and destroying habitat for the less common species associated with mature ecosystems. On the other hand, right-of-way vegetation that replaces natural forest may comprise a significant food source for deer and other ruminants (U.S. DOE, 1977).

Once the plant complex and power lines are completed, landscape disturbance ceases; human activity declines to a fraction of its construction-stage level, and land cleared during the construction stage but not required for operation (storage yards, waste sumps, parking lots, etc.) may be replanted.

The impact of an HDR system on visual quality depends on terrain and natural vegetation cover at the site. Landscape disturbance on a slope can be visible over a much larger area if other mountains do not block it from view. On the other hand, rugged terrain may reduce the visual impact of large vertical elements such as power line towers. The HDR plant complex itself is fairly unobtrusive except when natural-draft cooling towers are used; they must be up to eight times larger than mechanical-draft towers to handle the same thermal load. Far more obtrusive, in general, are the networks of roads, fluid lines, and power lines that extend over the landscape. The dirt or gravel roads and the low vegetation within the fluid- and power-line right-of-ways are most noticable in mountainous, forested areas where they contrast strikingly with the dark canopy vegetation. 


\section{Water Use}

A continuing source of water is required to replace water lost both to the HDR formation and, unless dry towers are used for heat rejection, to evaporation and blowdown as well. (The amount lost to drift is insignificant.) Permeation loss is expected to be minor; the loss rate at Fenton Hill declined rapidly to about $1 \%$ of the well flow rate (Heiken et al., 1981). The design flow rate of a power plant depends both on the temperature of the resource and on the secondary working fluid selected; optimizing for the latter would yield flows on the order of $3 \times 10^{5} \mathrm{~m}^{3} / \mathrm{y}^{\circ} \mathrm{MW}$ at $200^{\circ} \mathrm{C}$ and 6 to $8 \times 10^{5} \mathrm{~m}^{3} / \mathrm{y}^{\bullet} \mathrm{MW}$ at $150^{\circ} \mathrm{C}$ (Cummings and Morris, 1979). Rates of permeation loss will no doubt vary from one HDR formation to the next and may also increase with reservoir. size (Nunz, 1981).

The amount of makeup cooling water required depends on the resource temperature, ambient temperatures, water quality, and a number of other factors. Water quality is a factor because it governs the number of times water may be recycled through the tower before its solids content builds up to the point where it must be discharged as blowdown (the concentration factor). Robertson (1981) examined a broad range of climates and resource temperatures and, given typical values for the other factors, found projected makeup water consumption in essentially all cases to be between $5 \times 10^{4}$ and $10^{5} \mathrm{~m}^{3} / \mathrm{y}^{\cdot} \mathrm{MW}$ of net output using conventional, wet mechanical-draft towers. The consumption rate would of course be reduced to the extent dry towers are used to handle part or all of the cooling load. In wet/dry systems, the rate of water consumption is inversely related to capital cost; the optimal combination of wet and dry towers, however, is extremely sensitive to both plant and site conditions.

Loop and cooling water makeup will be drawn from rivers, lakes, or aquifers on or near the site. Lower flow volumes in rivers could produce stagnation, increased temperature, reduced oxygen content, silt deposition, and reduced water availability along the margins, which are often nursery areas for fish and other aquatic biota. The margins of lakes are also productive and provide nesting sites for wildfowl. While such marginal areas would eventually reestablish at the new water level, a marked drop could be expected to produce a decline in productivity for several years. On the other hand, in the semiarid-to-arid regions in which most of the HDR resource is located, plants are often dependent on near-surface groundwater and fish and wildlife on groundwater-fed springs and surface waterbodies. Lowering the water table could affect the diversity, productivity, and quantity of vegetation and significantly impact animal life (Woodward-Clyde, 1978). 
In the course of operation of an HDR energy system, dissolution of minerals in the formation rock will cause a rise in the total dissolved solids (TDS) content of the water in the closed reservoir loop. As the heat is extracted from the loop water at the surface, the solids could precipitate out as scale, clogging and ultimately plugging valves, pipes, and heat exchanger tubes. Certain minerals and gases can also cause corrosion of system components. Since the solubility of most minerals increases with temperature, in general the hotter a given resource the more likely some treatment of loop water may be required. Cummings et al. (1979) estimate a typical plant might have a solid waste output of 1 to $10 \mathrm{~kg} / \mathrm{d} \cdot \mathrm{MW}$ of silicate- or calcium carbonate-type material. At Fenton Hill, however, loop water TDS stabilized at under $2000 \mathrm{ppm}$, with no detectable evidence of corrosion or scaling (Nunz, 1980).

Another source of waste is cooling tower blowdown, which may be discharged to surface water, injected to a suitable aquifer, or evaporated in ponds. Cooling water contains biocides and elevated levels of both dissolved and suspended solids. Biocides are required because water circulating through cooling towers is an ideal habitat for microbial growth; it is warm, oxygenated, and receives a steady input of airborne organisms. If not prevented the microbial growth can insulate heat transfer surfaces; lodge in stagnant areas of the system, obstructing flow; and cause rot in wood and corrosion in iron tower components (Probstein and Gold, 1978). The solids content of cooling water is elevated because each time a given unit of water circulates through the tower, some percentage is lost via evaporation. Suspended solids, like microbial growth, tend to clog the system, while a variety of dissolved solids (e.g., $\mathrm{SiO}_{2}, \mathrm{CaCO}_{3}$, and $\mathrm{CaSO}_{4}$ ) precipitate out as scale as they reach their points of saturation. The periodic discharge of blowdown is necessary to keep the concentrations of both suspended and dissolved solids in the system within safe limits. Unfortunately, because the saturation points of dissolved solids are not exactly known, these limits tend to be set very conservatively in practice (Lihach, 1981).

The rate of blowdown discharge $B$ is given by:

$$
B=\frac{E}{C-1} \text {, }
$$

where $E$ is the tower evaporation rate and $C$ is the concentration factor. If, for example, $C=5$ and the total makeup rate $B+E=10^{5} \mathrm{~m}^{3} / y^{\circ} \mathrm{MW}$ (ignoring drift), then

$$
B=\frac{10^{5}}{5}=2 \times 10^{4} \mathrm{~m}^{3} / \mathrm{y} \cdot \mathrm{MW}_{\mathrm{e}} \text {. }
$$


However, the environmental impact of the waste produced depends not only on its volume but also on the method of disposal. Of the methods cited above, we do not expect untreated surface discharges to play a large role in the future. Most of the HDR resource is located in the semiarid-to-arid west, where river flows decline to very low volumes at precisely the time of year water use and blowdown discharge would be greatest. Most western states have or are moving toward a no-degradation policy for surface waters. Under such a policy surface-water discharge of blowdown could be practiced only if (1) the wastewater is treated to a quality equal to its original quality or (2) the receiving water body is different and of lower quality than the source water body. (Option 2 may also require some treatment, although not as much as option 1.)

Subsurface injection may also require some treatment of the blowdown, but limited in general to removal of suspended solids, which could plug the injection well. The feasibility of injection depends for the most part on the existence of a suitable nonpotable aquifer at moderate depth; however, data compiled by the U.S. EPA (1978) indicate that injection, on the average, is cheaper than any of the various treatment methods for removal of solutes.

Evaporation ponds require no treatment; they do, however, require huge amounts of land. Even in the hot arid west it takes up to a hectare of pond surface to evaporate $10 \mathrm{liter} / \mathrm{min}$ (Lihach, 1981). At the rate of blowdown discharge given in the example above, a 100-MW e plant would require over 400 ha of evaporation ponds. The ponds must have impervious liners to prevent contamination of near-surface groundwater. The volume of solid residue left after evaporation is greater than that produced by either preinjection or pre-surface-discharge treatment, since the former entails only removal of suspended solids and while the latter may entail removal of both suspended and dissolved solids, in general their concentrations must be reduced only to the levels of the receiving body of water. In evaporation ponds, on the other hand, the solid residue consists of the total suspended and dissolved solids content of the blowdown plus some residual water.

\section{Air Emissions}

Since binary conversion systems are closed loops, the only air emissions during normal plant operation are water vapor and drift from the wet cooling towers; dry towers produce no emissions. The vapor plumes may be visible for miles, and the localized rise in humidity can in turn increase fog and ice formation.

The impact of drift depends on the constituents of the cooling water, including biocides and other introduced substances as well as natural constituents. For example, at The Geysers boron contained in drift from the hydrothermal plants is believed to be the 
cause of foliar damage to nearby vegetation (Malloch et al., 1979). Unfortunately, only a limited amount of research has been performed on the biotoxicity of drift, and most of the work to date has dealt with conditions typical of the eastern U.S., that is, humid climate and eastern vegetation. Since relative humidity can influence the toxicity of drift, such work is of limited use for HDR resources, which are located predominately. in the dry western U.S. Moreover, the dispersion of drift is a complex phenomenon, and the development of models to simulate drift movement is still in progress (Molenkamp, 1980).

\section{Noise}

The noise produced by an operating plant can range from 75 to $85 \mathrm{dBa}$ at $15 \mathrm{~m}$ down to 40 to $45 \mathrm{dBa}$ at $800 \mathrm{~m}$ (Anspaugh and Leitner, 1980). The major source of noise would be mechanical-draft cooling towers, if used. Natural-draft towers are quieter than mechanical-draft towers, but in general are not suitable for hot climates where the difference between inside and outside temperatures would at times be insufficient to produce the air flow required.

The Environmental Protection Agency (EPA) requisite to ensure public welfare with an adequate margin of safety is an average day-night level of $55 \mathrm{dBa}$ for areas containing homes, schools, and hospitals. To maintain ambient noise within this limit would require a separation of, at most, $0.5 \mathrm{~km}$ between such areas and an HDR plant. The continuous noise produced by an operating plant is unlikely to have a significant impact on wildlife; the level of human activity is more important since some species tend to abandon areas that are too frequently disturbed (U.S. DOE, 1977).

\section{Accidental Emissions}

While under normal operation an HDR plant would produce almost no emissions, mishaps are possible that could lead to short-duration vapor or fluid releases. Sump failures and releases of unanticipated hydrothermal fluid are confined to the resource confirmation and field development stages, however. During operation of the HDR system, the only potential mishaps of importance are pipe ruptures and well casing or packing failures.

Well casing may rupture because of earthquakes, landslides, or corrosion. The cement packing around the casing is intended to contain the fluids in the well in the event of casing failure; however, the displacement caused by an earthquake or landslide may rupture the packing as well. Inadequate cementing has proven to be a problem at Fenton Hill; the thermal shocks produced in fracturing and heat extraction caused the 
casing-packing bond in one of the wells to deteriorate to the point where recementing was required. By the time the system was shut down for recementing, water loss up the annulus between casing and packing amounted to $80 \mathrm{liter} / \mathrm{min}$ (Cremer et al., 1980). Such leakage of HDR fluid up the wellbore could contaminate overlying potable aquifers, if present; however, HDR fluid is not expected to be toxic enough to have a significant impact on groundwater quality (U.S. DOE, 1977).

Ruptured pipes may cause intense but short-duration spills. The greatest concern is a leak of isobutane or some other volatile working fluid, which could in turn lead to a dangerous flash fire. While such fires would as a rule be contained onsite, ignition of surrounding vegetation is possible, especially in dry climates with a high concentration of biomass per unit of land. Loop water released from a pipe rupture would flash to steam, resulting in both volatization of dissolved gases and deposition of any biotoxic substances contained in the fluid on nearby vegetation. Since the concentrations of dissolved gases and solids are expected to be very low in loop water (Gutschick and Rea, 1978), damage would be limited to that caused by heat.

\section{Employment}

Again, the employment impacts of HDR plants are expected to be similar to those of hydrothermal plants. Construction of a $100-\mathrm{MW}$ e plant takes about 2 y and employs a peak of about 80 workers. Operation of the first plant brought on-line by a given utility requires a base staff of about 20 ; subsequent plants by the same utility, however, would require additional staff of only about 4 per plant (Haven et al., 1980). In their aforementioned study of The Geysers, Lofting and Hall (1981) estimate that each job .created directly in the electric companies and systems sector results in 0.6 indirect and 1.2 induced jobs.

\section{ABANDONMENT}

Fields may be abandoned because of changes in the relative value of HDR energy or depletion of the resource. All surface improvements will be removed and the wells shut

in, leaving an extensively disturbed landscape. The dismantling and removal of improvements entails the use of the same type of heavy equipment that brought it in the first place, with potential impacts as described under General Construction. 
Regrading and replanting of the raw, disturbed land that remains is usually required by the state or locality. While the land would begin to revert to its predevelopment condition in the absence of such restoration, in some places the successional stages involved can take 50 to $100 \mathrm{y}$. During the interim, damage can occur that permanently alters the ecosystem (e.g., soil erosion and changes in faunal populations).

\section{POTENTIAL ENVIRONMENTAL IMPACTS}

The following discussion of environmental concerns' potential to impede HDR commercialization is based on the information shown in Table 1 , that is, site variables that may influence the severity of impacts, major uncertainties in impact prediction, and available control measures.

\section{LANDSCAPE DISTURBANCE}

Landscape disturbance in an HDR field is expected to range from 10 to $20 \%$ of the total acreage, given a conventional layout of one well pair per pad. In general, the lower end of this range would apply in flat or nearly flat terrain and the upper end in rugged terrain because of the earth-moving required to create flat roads and pads in the latter. As long as the standard erosion control practices listed in Table 1 are employed and disturbed land is restored, the impacts of landscape disturbance should be insignificant except at critical ecological sites (e.g., wetlands; habitats of rare species; or mating, nesting, or wintering grounds) or sites of particular visual, recreational, or cultural value. In some such instances it may be necessary to forego HDR development entirely. In others, however, careful design might permit some development. A key means of reducing disturbance, at some penalty in cost, is to drill all wells from one or two central pads. Since the need for roads and fluid line right-of-ways declines with the number of pads, the use of multiwell pads might reduce the landscape disturbance typical of conventional layouts by up to half.

Once construction is completed, disturbed land not required for system operation should be replanted. Such land (storage yards, waste sumps, parking lots, etc.) can comprise up to half the total disturbed. In rugged terrain, the raw slopes created by cutting or filling should also be replanted. The land may either be restored to its predevelopment condition or its habitat value may be improved by altering the plant 
TABLE 1. Environmental and socioeconomic concerns of HDR energy development.

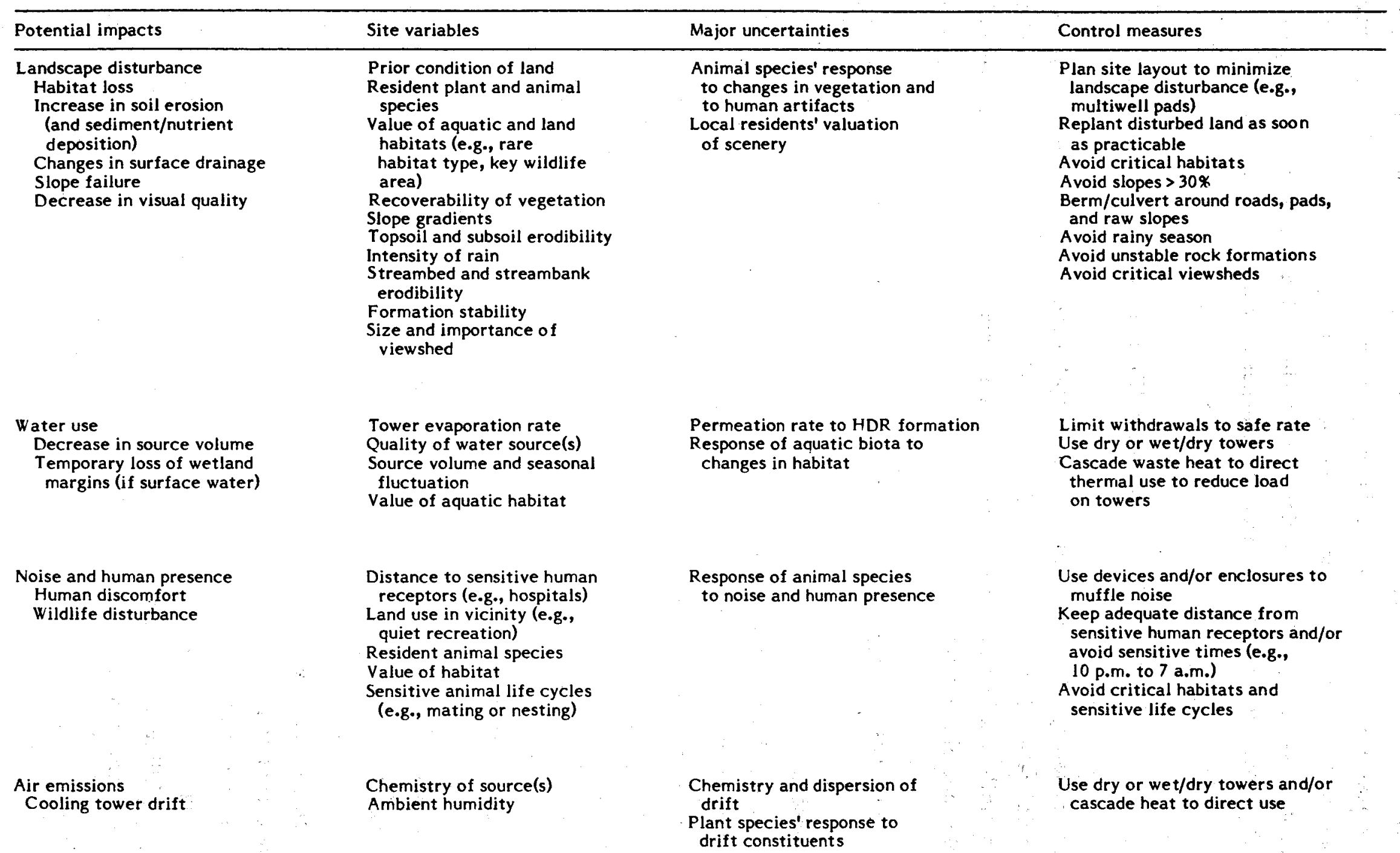


TABLE 1. (Continued.)

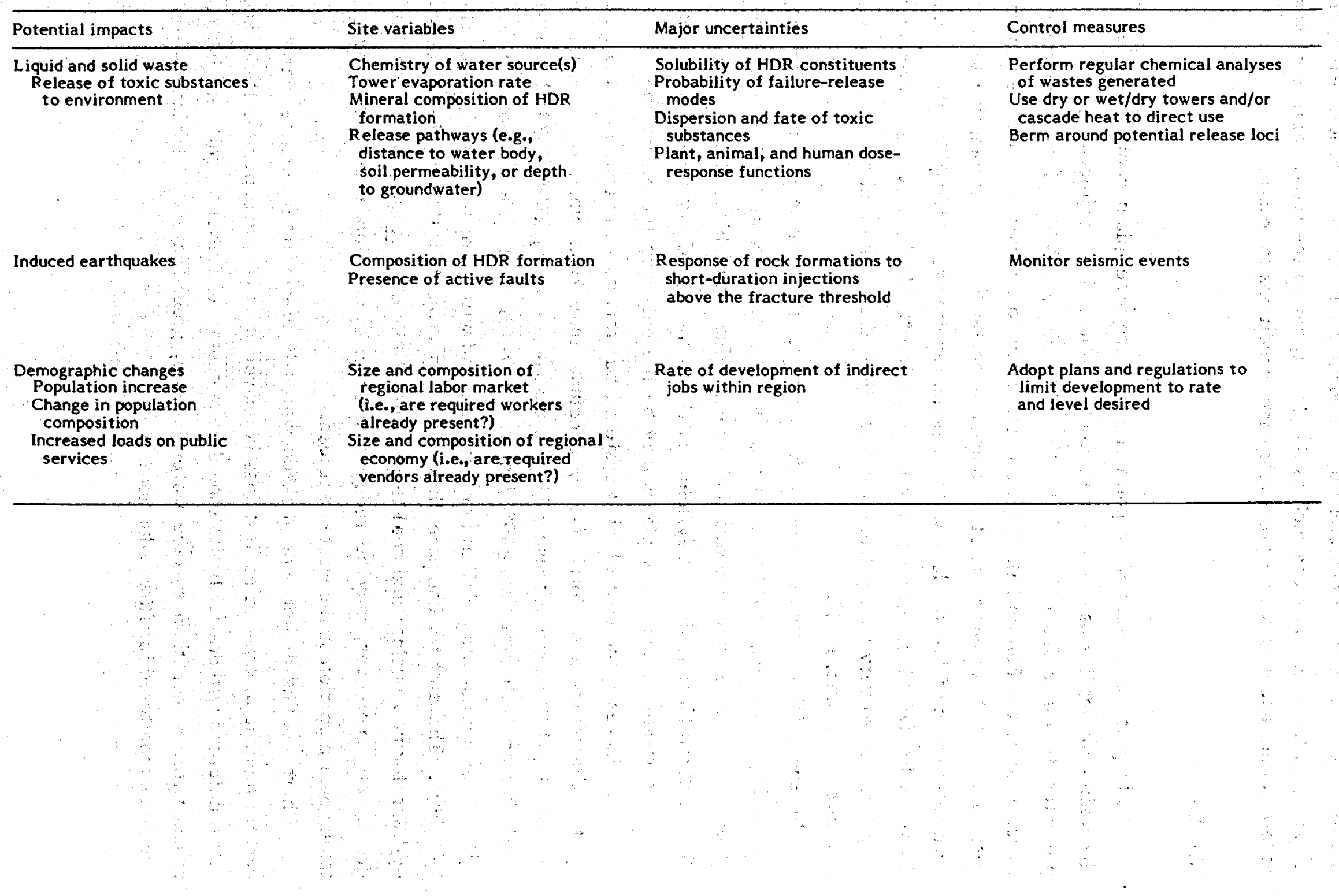


mosaic (e.g., create more ecotones) by introducing new plant varieties. Revegetation is no panacea, however. In areas such as the desert, where the recoverability of vegetation is low, it can take decades for predevelopment conditions to return.

\section{WATER USE}

As long as wet towers or evaporation ponds are used, plant cooling represents by far the main consumptive use of water in HDR systems. The cooling water makeup rate is projected to range from $5 \times 10^{6}$ to $10^{7} \mathrm{~m}^{3} / \mathrm{y}$ per $100-\mathrm{MW}$ e plant (Robertson, 1981). Experience at the Fenton Hill project would seem to indicate the replacement of water lost to the HDR formation is of secondary importance as a consumptive use. At their permeation rate of $1 \%$, the loop water makeup required for a $100-\mathrm{MW}$ e plant would range from $3 \times 10^{5}\left(200^{\circ} \mathrm{C}\right.$ fluid) up to $8 \times 10^{5} \mathrm{~m}^{3} / \mathrm{y}\left(150^{\circ} \mathrm{C}\right.$ fluid). However, permeation rates may turn out to vary widely from one formation to the next and may also increase with fracture size (Nunz, 1981).

In some HDR resource areas, for example those in Idaho and Oregon, water availability is not expected to be a significant constraint, at least in this century. In other areas, for example Nevada and New Mexico, available water is already close to $100 \%$ utilized (Shepherd and Mayfield, 1981) and the use of dry towers to handle part or all of the waste heat of HDR plants may be the only way the plants can be built. Dry towers do increase the cost of HDR systems, but this cost increase is not prohibitive in itself. Cummings and Morris (1979) conclude that even when dry towers are used exclusively, HDR energy is feasible (1) at a busbar cost of $3 \notin / \mathrm{kW} \cdot \mathrm{h}(1978 \$)$ with gradients $\geq 50^{\circ} \mathrm{C} / \mathrm{km}$ and with gradients $\geq 40^{\circ} \mathrm{C} / \mathrm{km}$ at flow rates $>50 \mathrm{~kg} / \mathrm{s}$ and (2) at a busbar cost of $4 \not / \mathrm{kW} \cdot \mathrm{h}$ with gradients $\geq 40^{\circ} \mathrm{C}$ at any flow rate and with gradients $\geq 30^{\circ} \mathrm{C} / \mathrm{km}$ at flow rates $>75 \mathrm{~kg} / \mathrm{s}$. The authors compare these costs to projected 1985 to 1990 costs of 3 to $6 \notin / \mathrm{kW} \cdot \mathrm{h}$ for new nuclear and coal-fired plants (Cummings et al., 1979). The net cost of dry towers, moreover, may be reduced in some circumstances by direct-heat systems taking over a portion of the waste heat load.

Where cooling and/or loop makeup water is drawn from surface water bodies, a certain amount of aquatic habitat loss is unavoidable; but, except at critical ecological sites, enforced withdrawal limits should be adequate to prevent significant harm. Where groundwater rather than surface water is used, groundwater-fed surface water bodies should be monitored for flow reductions. 


\section{NOISE AND HUMAN PRESENCE}

While construction, drilling, and plant operation produce noise $(75$ to $90 \mathrm{dBa})$ that at close range is annoying to humans, it can be reduced adequately by devices or enclosures (Leitner, 1980). The impact of noise and human presence on wildlife is not well understood, but animals that rely on sound for hunting or defense could suffer auditory damage and critical activities such as mating, nesting, and hibernation could be disrupted. Beyond the human presence due to the HDR facility itself, the roads built to service the facility could in certain instances provide vehicular access to previously remote areas. At sites where this could result in significant harm to wildlife the roads should be gated.

\section{AIR EMISSIONS}

Emissions from construction and drilling equipment are insignificant. The vapor plumes produced by wet cooling towers can be visible for miles and can contribute to localized fog and ice formation, but otherwise have no impact. Neither the composition nor the dispersion of wet cooling tower drift can be predicted with current methods (Molenkamp, 1980). The biotoxicity of drift is of some concern in the case of flashed-steam hydrothermal plants, which use the steam condensate as cooling water, since the mineral content of hydrothermal fluids can be extremely high. Since binary HDR plants must draw cooling water from an external source, the biotoxicity of drift from such plants should in general be far lower and comparable to conventional plants.

\section{LIQUID AND SOLID WASTE}

The only significant source of waste in an HDR system is blowdown from wet cooling towers, which may be disposed of as a liquid (by injection) or a solid (by pond evaporation). The volume of waste in either case depends on cooling water quality, which in turn governs the concentration factor. Injection is the preferable method because of the huge land requirements of evaporation ponds: over 400 ha per $100-\mathrm{MW}$ e plant given a discharge rate of $2 \times 10^{6} \mathrm{~m}^{3} / \mathrm{y}$ and an evaporation rate of $10 \mathrm{liter} / \mathrm{ha} \cdot \mathrm{min}$.

Of greater concern than the volume of waste, however, is its toxicity. Wastes from drilling, loop water treatment, and tower blowdown all have at least the potential to contain toxic substances. Chemical analyses must be performed on a case by case basis to determine whether any of the wastes from HDR systems require special disposal methods (Morris and Layton, 1980). 
While it has been demonstrated that earthquakes can be induced by prolonged fluid injection at a pressure above the threshold pressure of the receiving formation (Raleigh et al., 1975), there is no evidence to date of perceptible earthquakes induced by short-duration injections. Downhole instruments at Fenton Hill have detected microearthquakes of magnitudes -6 to -2 coincident with hydrofracturing (Albright, 1979). While of no significance in themselves, being orders of magnitude below the range of human perceptibility, it is unknown whether such events have the potential to trigger larger earthquakes in regions of active faults. Since much of the HDR resource lies in areas of moderate-to-high seismic risk, monitoring at development sites is necessary, at least until more evidence is compiled on seismic response to short-duration injections. Experience to date, however, suggests the risk of hydrofracturing is very low (Crow, 1981 ).

\section{ACCIDENTAL EMISSIONS}

Accidental emissions possible at an HDR facility include sump failure or leakage, casing or packing failure, release of hydrothermal fluid, and pipe rupture. Given normal care in lining waste sumps, leakage is not expected to be a problem because of their short life. Avoidance of weak or slide-prone soil can reduce the probability of casing or packing failure. However, cementing has proven to be a problem in high-temperature wells and some risk of failure, and thus of fluid migration, remains. Because HDR fluids are expected as a rule to be of very low toxicity though, this risk is not significant. Avoidance of weak or slide-prone soil can also reduce the probability of failure of the sump wall. Berms can be built around sumps and (if there is a chance hydrothermal fluid may be encountered) pads to contain fluid releases. A hydrothermal blowout of any duration would soon overflow the berm, but blowouts of this sort are extremely unlikely in HDR development.

Pipe ruptures may involve either loop water, working fluid, or cooling water. Beyond direct injury to plant workers, the main concern is the risk of fire from a release of a volatile working fluid such as isobutane. As a rule, such a release would be contained within the plant complex site and as long as vegetation on the site itself is managed adequately, the risk of the fire spreading offsite should be minimal. 


\section{POTENTIAL SOCIOECONOMIC IMPACTS}

Operation of an HDR energy system requires a minimal work force ( 20 for the first plant and 4 for each subsequent plant by the same utility); moreover, the multiplier effects of system operation on the region are relatively low (1.8 jobs for each job created directly). Thus, the only employment impacts of potential significance are those of field development and plant construction.-Each drilling rig employs 20 to 25 workers. However, to complete an HDR system within a reasonable time frame, several rigs would have to operate simultaneously. For example, if a given $100-\mathrm{MW}$ plant required 12 well pairs and each well took 6 mo to complete, to complete the entire field in 2 y would require 6 .rigs and 120 to 150 rig workers. Site preparation requires a crew of about ten for each drilling site; but one or two crews working continuously should be adequate for an entire field. Construction of a typical $100-\mathrm{MW}$ plant takes about 2 y and employs a peak of about 80 workers (Haven et al., 1980).

The site preparation and plant construction work forces will be drawn from the regional labor market in all but the most sparsely populated areas. Drilling personnel will be imported from outside the region and, at least until a large stable HDR industry develops in the region, will depart once their job is completed. Since rig workers are almost entirely single men or men whose families do not travel with them, they tend not to require much in the way of public services nor are they numerous enough to create serious social disruptions (e.g., prostitution and alcoholism). Housing is likely to be a problem in small towns. Trailer camps, as long as they are responsibly managed, can be used for single projects but in areas of ongoing HDR development more permanent facilities (e.g., those with water and septic hookups and paved roads) should be provided for by the developer.

Of greater significance than the jobs directly created by HDR development are the indirect and induced jobs that result from it. While the multiplier effects of site preparation and plant construction are on the low-to-moderate side, those of drilling and related tasks are anticipated to be very large: 4.3 indirect and 2.5 induced jobs are projected for every direct job at The Geysers hydrothermal resource (Lofting and Hall, 1981). The 120 to 150 drilling jobs in the above example would thus create 800 to 1000 additional jobs. However, the indirect figures cited for The Geysers region cannot be used indiscriminately; they would be applicable only to regions with a sizable HDR industry already in place. Firms that provide materials or services used by the industry are not apt to invest in a regional operation until a reasonably long-term market is established; any significant increase in indirect jobs, therefore, would be permanent rather than transient in nature. Until such a long-term market is established, materials and services not already obtainable in the region will be imported. 
Much has been written about the boomtown syndrome caused by large-scale energy development in sparsely populated areas of the western U.S. The term has been used in the literature to refer both to a large and rapid rise in population due to worker in-migration and, in a more limited sense, to a large increase followed in a few years by a large decrease. The latter pattern is characteristic of developments that (like HDR) require much larger work forces for construction than for operation. A sharp rise in population can impose significant temporary hardships on a small, isolated town, but if the increase is a permanent one the town should, over time, regain its social and fiscal equilibrium. The old close-knit, slow-paced way of life, however, may be gone forever. A boom-and-bust cycle, on the other hand, can be more devastating. Social disruption tends to be greater since the transient workers have no long-term stake in the community. The community also faces a dilemma with respect to public services it can either make heavy investments on services for the transients, knowing they will be superfluous in a few years or they can endure severely overtaxed services plus the social and environmental consequences they bring about. These consequences (e.g., aquifer depletion, groundwater contamination, or low-quality education) may continue to be felt long after the transients' departure.

Gilmore (1976) in his article on energy boomtowns contends that population increases of $15 \%$ or more (within a short period of time) lead to institutional breakdowns in the fiscal system and the housing and labor markets. The multipliers calculated for The Geysers region suggest that sustained HDR development has the potential to cause such impacts, at least in the more remote areas of the western U.S. However, the impacts would be more of a boom than a boom and bust nature, since the jobs created by HDR development would be predominantly indirect rather than direct and thus for the most part permanent rather than transient.

Control of the social and fiscal impacts of HDR is largely a matter of (1) deciding what pace and ultimate level of development the region can accommodate and (2) adopting regulations to keep development within those limits. This is far easier said than done of course. In the first place, HDR resources overlap county (and often state) boundaries, so the state (or some type of regional body) may be the only viable regulatory authority. Moreover, in general the more rural an area and the slower its historical rate of change, the more hostile its residents are to the idea of government plans and regulations. What advance regulatory measures are taken are likely to be motivated more by concerns over competition for water (and possibly land) resources than by socioeconomic concerns, which are inherently more speculative. 


\section{BIBLIOGRAPHY}

Albright, J., Seismic investigations, Summary of Talks: 3rd Annual Hot Dry Rock Geothermal Information Conference, Santa Fe, NM, October 28-29, 1979.

Anspaugh, L., and P. Leitner, Health and safety concerns, in An Assessment of

Geothermal Development in the Imperial Valley, D. Layton, Ed., U.S. Department of Energy, Washington, DC, DOE/EV-0092 Vol. 1 (1980), Pp. 10-1 - 10-21.

Cremer, G., R. Duffield, M. Smith, and M. Wilson, Hot Dry Rock Geothermal Energy Development Program: Annual Report, Fiscal Year 1979, Los Alamos National Laboratory, Los Alamos, NM, LA-8280-HDR (1980).

Crow, N., Lawrence Livermore National Laboratory, private communication (September 1981).

Cummings, R., G. Morris, J. Tester, and R. Bivins, Mining Earth's heat: hot dry rock geothermal energy, Technol. Rev., 58-78 (February 1979).

Cummings, R., and G. Morris, Economic Modeling of Electricity Production from Hot Dry Rock Geothermal Reservoirs: Methodology and Analyses, Electric Power Research Institute, Palo Alto, CA, EPRI EA-630 (1979).

Garnish, J. D., Progress in geothermal energy, Endeavour 2 (2), 66-71 (1978).

Gilmore, J. S., Boom towns may hinder energy resource development, Science 191, $535-540(1976)$.

Goodwin, J. G., Big Game Movement Near a 500 kV Transmission Line in Northern Idaho, Bonneville Power Administration, Portland, OR (1975).

Gutschick, V., and K. Rea, Environmental Assessment of Dissolved Gases in LASL's Hot Dry Rock Geothermal Source Demonstration Project, Los Alamos Scientific Laboratory, Los Alamos, NM, LA-UR-78-919 (1978). 
Haven, K., V. Berg, and Y. Ladson, Local Population Impacts of Geothermal Energy Development in The Geysers-Calistoga KGRA Region, Lawrence Berkeley National Laboratory, Berkeley, CA, LBL-10150 (1980).

Heiken, G., H. Murphy, G. Nunz, R. Potter, and C. Grigsby, Hot dry rock geothermal energy, Am. Sci. 69, 400-407 (1981).

Kercher, J., and D. Layton, Impacts on agricultural resources, in An Assessment of Geothermal Development in the Imperial Valley of California, D. Layton, Ed., U.S. Department of Energy, Washington, DC, DOE/EV-0092 Vol. 1 (1980), pp. 9-1 - 9-20.

Kron, A., and G. Heiken, Geothermal Gradient Map of the Conterminous United States, Los Alamos Scientific Laboratory, Los Alamos, NM, LA-8476-MAP (1980).

Layton, D., and N. Crow, Subsidence and seismicity, in An Assessment of Geothermal Development in the Imperial Valley of California, D. Layton, Ed., U.S. Department of Energy, Washington, DC, DOE/EV-0092 Vol. 1 (1980), pp. 8-1 - 8-26.

Leitner, P., Noise control technologies, in An Assessment of Geothermal Development in the Imperial Valley of California, W. Morris and J. Hill, Eds., U.S. Department of Energy, Washington, DC, DOE/EV-0092 Vol. 2 (1980), pp. 58-70.

Lihach, N., Balancing the water budget, EPRI J. 6(5), 6-11 (1981).

Lofting, E., and C. Hall, The Potential Impacts of Geothermal Energy Development on the Four County Geysers Region, California, Lawrence Livermore National Laboratory, Livermore, CA (in press, 1981).

Malloch, G., M. Eaton, and N. Crane, Assessment of Vegetation Stress and Damage Near The Geysers Power Plant Units, Pacific Gas and Electric Company, San Francisco, CA, Report 420-79 (1979).

Molenkamp, C., Control technologies for the abatement of cooling tower drift, in An Assessment of Geothermal Development in the Imperial Valley of California, W. Morris and J. Hill, Eds., U.S. Department of Energy, Washington, DC, DOE/EV-0092 Vol. 2 (1980), pp. 34-57. 
Morris, W., and D. Layton, Liquid and solid wastes, in An Assessment of Geothermal Development in the Imperial Valley of California, D. Layton, Ed., U.S. Department of Energy, Washington, DC, DOE/EV-0092 Vol. 1 (1980), pp. 7-1 - 7-15.

Mortensen, J., The LASL Hot Dry Rock Energy Development Project, Los Alamos Scientific Laboratory, Los Alamos, NM, LASL Mini-Review 77-8 (1977).

Nunz, G., A status report: hot dry rock geothermal energy, Mech. Eng., 26-31 (November 1980).

Nunz, G., Los Alamos National Laboratory, Los Alamos, NM, private communication (September 1981).

Pettitt, R., Hot dry rock: a new potential for energy, Geotherm. Energy Mag. 6(11), 11-19 (1978).

Pettitt, R., and J, Tester, The Development of Hot Dry Rock Resources, Los Alamos Scientific Laboratory, Los Alamos, NM, R-78-1336 (1978).

Prestwich, S., Low temperature drilling techniques for direct use applications, in Commercial Uses of Geothermal Heat, Geothermal Resources Council, Davis, CA, Special Report \#9 (1980), pp. 97-98.

Probstein, R., and H. Gold, Water in Synthetic Fuel Production: the Technology and Alternatives (MIT Press, Cambridge, MA, 1978).

Raleigh, D., J. Healy, and J. Bredehoeft, An experiment in earthquake control at Rangely, Colorado, Science 191, 1230-1237 (1975).

Robertson, R., Geothermal power station water requirements, in Water-Related Constraints to the Development of Geothermal Electric Generating Stations, Oak Ridge National Laboratory, Oak Ridge, TN, ORNL/TM-7718 (1981), pp. 2-1 - 2-24.

Shepherd, A., and M. Mayfield, Resources profiles and water availability situation, in Water-Related Constraints to the Development of Geothermal Electric Generating Stations, Oak Ridge National Laboratory, Oak Ridge, TN, ORNL/TM-7718 (1981), pp. 3-1-3-43. 
Smith, M., Los Alamos National Laboratory, Los Alamos, NM, private communication (August 1981).

SRI International, Consultant Report on Environmental Analysis for Geothermal Energy Development in the Geysers Region: Vol. 2, California Energy Resources Conservation and Development Commission, Sacramento, CA (1977).

U.S. DOE, Environmental Impact Assessment: Hot Dry Rock Subprogram, U.S. Department of Energy, Washington, DC, EIA/GE/77-6 (1977).

U.S. EPA, Western Energy Resources and the Environment: Geothermal Energy, U.S. Environmental Protection Agency, Washington, DC, EPA-600/9-77-010 (1977).

U.S. EPA, Pollution Control Guidance for Geothermal Energy Development, U.S. Environmental Protection Agency, Washington, DC, EPA-600/7-78-101 (1978).

Woodward-Clyde Consultants, Impact Prediction Manual for Geothermal Development, U.S. Fish and Wildlife Service, Washington, DC, FWS/OBS-78/77 (1978). 